\title{
Multiple Metal Binding Domains Enhance the Zn(II) Selectivity of the Divalent Metal Ion Transporter AztA ${ }^{\dagger}$
}

\author{
Tong Liu $\ddagger$, Hermes Reyes-Caballero $\ddagger$, Chenxi Li§, Robert A. Scott§, and David P. Giedroc ${ }^{\star}, \ddagger$ \\ Department of Biochemistry and Biophysics, Texas A\&M University, College Station, Texas \\ 77843-2128, and Department of Chemistry and Center for Metalloenzyme Studies, University of \\ Georgia, Athens, Georgia 30602
}

\begin{abstract}
Transition metal-transporting $\mathrm{P}_{1 \mathrm{~B}}$-type CPx ATPases play crucial roles in mediating metal homeostasis and resistance in all cells. The degree to which $\mathrm{N}$-terminal metal binding domains (MBDs) confer metal specificity to the transporter is unclear. We show that the two MBDs of the $\mathrm{Zn} / \mathrm{Cd} / \mathrm{Pb}$ effluxing pump Anabaena AztA are functionally nonequivalent, but only with respect to zinc resistance. Inactivation of the a-MBD largely abrogates resistance to high intracellular $\mathrm{Zn}$ (II) levels, whereas inactivation of the b-MBD is not as deleterious. In contrast, inactivation of either the a- or b-MBD has little measurable impact on $\mathrm{Cd}(\mathrm{II})$ and $\mathrm{Pb}(\mathrm{II})$ resistance. The membrane proximal b-MBD binds $\mathrm{Zn}$ (II) with a higher affinity than the distal N-terminal a-MBD. Facile $\mathrm{Zn}$ (II)-specific intermolecular transfer from the a-MBD to the higher-affinity b-MBD is readily observed by ${ }^{1} \mathrm{H}-{ }^{15} \mathrm{~N}$ HSQC spectroscopy. Unlike $\mathrm{Zn}(\mathrm{II}), \mathrm{Cd}(\mathrm{II})$ and $\mathrm{Pb}$ (II) form saturated 1:1 $\mathrm{S}_{4}$ or $\mathrm{S}_{3}(\mathrm{O} / \mathrm{N})$ complexes with $\mathrm{AztA}^{\mathrm{aHbH}}$, where a single metal ion bridges the two MBDs. We propose that the tandem MBDs enhance $\mathrm{Zn}$ (II)-specific transport, while stabilizing a non-native inter-MBD $\mathrm{Cd} / \mathrm{Pb}$ cross-linked structure that is a poor substrate and/or regulator for the transporter.
\end{abstract}

Complex metal homeostasis and trafficking systems control the bioavailability of essential transition metal ions while ensuring that these and other abiological xenobiotics, including $\mathrm{Cd}, \mathrm{Pb}, \mathrm{Hg}$, and $\mathrm{As}$, do not accumulate inside cells. The heavy metal ion-transporting CPxATPases represent a large subfamily of P-type ATPases $\left(\mathrm{P}_{1 \mathrm{~B}}\right.$-type) found in both prokaryotes and eukaryotes that play important roles in metal homeostasis (1-5). All are characterized by eight transmembrane (TM) ${ }^{1}$ helices that likely form the channel for transport. TM6 bears the CPx signature sequence, which is thought, in conjunction with

\footnotetext{
$\dagger^{\dagger}$ This work was supported by grants from the National Institutes of Health (NIH) (GM042569 to D.P.G. and GM042025 to R.A.S.) and the Robert A. Welch Foundation (A-1295 to D.P.G.). Portions of this research were carried out at the Stanford Synchrotron Radiation Laboratory (SSRL), operated by Stanford University on behalf of the U.S. Department of Energy, Office of Basic Energy Sciences. The SSRL Structural Molecular Biology Program is supported by the Department of Energy, Office of Biological and Environmental Research, and by the NIH National Center for Research Resources, Biomedical Technology Program.

(C) 2007 American Chemical Society

"To whom correspondence should be addressed: Department of Chemistry, Indiana University, 800 E. Kirkwood Ave., Bloomington, IN 47405-7102. Telephone: (812) 856-5449. Fax: (812) 855-8300. giedroc@indiana.edu..

*Texas A\&M University.

§University of Georgia.

SUPPORTING INFORMATION AVAILABLE Tables of sedimentation equilibrium, EXAFS curve fitting results, and resonance assignments; HPLC size exclusion chromatographic analysis, HSQC spectra, chemical shift difference plots, and electrostatic surface potential renderings of homology models; and supplementary methods. This material is available free of charge via the Internet at http://pubs.acs.org.

${ }^{1}$ Abbreviations: ArsR, arsenic repressor; azt, Anabaena zinc transport; AztA ${ }^{\mathrm{aH}}, \mathrm{N}$-terminal a-MBD with a His-rich tail (residues 1105); $\mathrm{Azt}^{\mathrm{aHbH}}$, complete MBD of AztA (residues 1-213); mag-fura-2, 2-\{6-[bis(carboxymethyl)amino]-5-(carboxymethoxy)-2benzofuranyl\}-5-oxazolecarboxylic acid; MBD, metal binding domain; TM, transmembrane.
} 
other residues in the membrane helices, to coordinate the metal during transport (6). Large cytoplasmic loops are folded into structurally characterized actuator (7) [A-domain (Figure 1A)] and ATP binding domains $(8,9)(\mathrm{N}$ - and P-domains), with metal translocation coupled to phosphorylation of an aspartate residue in the P-domain.

Another significant feature of CPx-ATPases is that most have N-terminal and/or C-terminal cytosolic extensions, often containing one or more tandemly linked ferredoxin fold-like $\beta a \beta \beta a \beta$ metal binding domains (MBDs) (Figure 1A) (10). For example, the Wilson's and Menkes disease $\mathrm{Cu} / \mathrm{Ag}$-specific ATPases ATP7A and ATP7B, respectively, have six tandemly linked MBDs, while those from lower eukaryotes and most prokaryotes have zero, one, or two MBDs. These MBDs are known to provide docking sites for $\mathrm{Cu}$ chaperones that allow $\mathrm{Cu}$ to be handed off, via intermolecular metal-ligand exchange reactions, to partner MBDs without dissociation of the metal into bulk solution (11-14). This provides strong support for the central tenet of the Cu-trafficking hypothesis $(15,16)$. Mechanistic studies with Archaeglobus fulgidis CopA suggest that metal binding to the single N-terminal MBD plays a regulatory role in enhancing the rate of dephosphorylation of the phosphoaspartate residue in the E2 state; this increases the rate of metal ion release which is rate-limiting in multiple-turnover experiments (17).

Some divalent metal ion $(\mathrm{Zn} / \mathrm{Cd} / \mathrm{Pb})$-specific $\mathrm{P}_{1 \mathrm{~B}}$-type ATPases (2) are also known to possess an MBD, but the functional role that this domain plays is a topic of ongoing investigation. Since there are no known zinc chaperones, the significance of protein-protein docking and intermolecular transfer is unclear. However, there is some evidence in support of the idea that the specific structural features of individual MBDs might provide some metal selectivity to the transporter itself, despite the fact that they all adopt essentially the same $\beta a \beta \beta a \beta$ fold (10) and all metal complexes employ the two conserved Cys residues of the CXXC sequence as metal donor atoms (18-21). For example, in both copper chaperones and MBDs derived from $\mathrm{Cu} / \mathrm{Ag}$ transporters, the $\mathrm{Cu}(\mathrm{I})$ is often coordinated via a linear bisthiolate complex (22-24); in another case, a distorted trigonal $\mathrm{S}_{2} \mathrm{~N}$ complex is found, where a His derived from loop 5 between helix a 2 and strand $\beta 4$ is a ligand (25). For the $\mathrm{Zn} / \mathrm{Cd} / \mathrm{Pb}$ transporter Escherichia coli ZntA, a conserved Asp just N-terminal to the first Cys

(DCXXC) was proposed to drive 3- or 4-coordination of $\mathrm{Zn}$ (II) (19); in contrast, for the $\mathrm{Cd}$ / $\mathrm{Pb}$-selective transporter Listeria monocytogenes $\mathrm{CadA}$, a conserved Glu in loop 5 (E61 in Figure 1B) appears to form a coordination bond to the $\mathrm{Cd}(\mathrm{II})$ in a binuclear homodimeric subunit bridging structure (20).

Anabaena AztA (alr7622) is a $\mathrm{P}_{1 \mathrm{~B}}$-type ATPase efflux pump encoded by the azt (Anabaena zinc transport) operon whose expression is transcriptionally induced upon direct binding of $\mathrm{Zn}, \mathrm{Pb}$, or $\mathrm{Cd}$ by the ArsR (or ArsR/SmtB) family (26) regulator AztR (27). AztA possesses the unique functional property of conferring significant $\mathrm{Zn}$ (II) resistance to a transformed $\mathrm{Zn} / \mathrm{Cd} / \mathrm{Pb}$-hypersensitive E. coli strain (GG48), relative to $\mathrm{Cd}(\mathrm{II})$ and $\mathrm{Pb}(\mathrm{II})$ (27). In fact, cadmium and lead resistance is barely detectable relative to that conferred by other known $\mathrm{Pb} / \mathrm{Cd} / \mathrm{Zn}$-transporting ATPases, including E. coli ZntA (28) and CadAs from Streptomyces aureus, Ralstonia metallodurans, and L. monocytogenes (29). AztA is also distinguished from other characterized $\mathrm{Zn} / \mathrm{Cd} / \mathrm{Pb}$ transporters on the basis of harboring two $\mathrm{N}$-terminal MBDs, each of which is followed by an $\approx 30$-residue hydrophilic His-rich linker (Figure 1). The two MBDs of AztA are 44\% identical, pairwise, in amino acid sequence (71\% similar), and each contains a DCXXC sequence and lacks the Glu in loop 5 found in CadAs. Since AztA is unique in incorporating tandem MBDs followed by His-rich segments, this led us to hypothesize that some aspect of these specific features might confer higher selectivity for $\mathrm{Zn}$ (II) relative to $\mathrm{Cd}$ (II) and $\mathrm{Pb}$ (II). 
In this report, we show that the two MBDs of Anabaena AztA play nonredundant structural and functional roles in metal binding and heavy metal resistance in vivo, but only with respect to zinc resistance. We show that the membrane proximal b-MBD has a higher affinity for $\mathrm{Zn}$ (II) than the distal a-MBD, and consistent with this, $\mathrm{Zn}$ (II) prebound to the aMBD facilely moves to a metal-free b-MBD. However, the low-affinity a-MBD plays a critical role in mediating zinc resistance under conditions of high zinc toxicity in a manner that does not require the b-MBD. This suggests that the a-MBD is capable of functioning in a manner independent of the b-MBD in maximally stimulating transport under high intracellular zinc loads. In contrast, both $\mathrm{Cd}(\mathrm{II})$ and $\mathrm{Pb}$ (II) form stable $1: 1 \mathrm{~S}_{4}$ or $\mathrm{S}_{3}(\mathrm{~N} / \mathrm{O})$ complexes in $\mathrm{Azt}^{\mathrm{aHbH}}$, where a single metal ion bridges the two Cys- $\mathrm{X}_{2}$-Cys sites from aand $\mathrm{b}-\mathrm{MBDs}$ or forms intermolecular $\mathrm{a}-\mathrm{a}^{\prime}$ and $\mathrm{b}-\mathrm{b}^{\prime}$ cross-linked structures. We hypothesize that these structures represent kinetically trapped intermediates that are poor substrates or regulators for metal transport by AztA.

\section{MATERIALS AND METHODS}

\section{Plasmid Construction of Wild-Type and Mutant azt Operons and Metal Sensitivity Assays}

The complete azt operon (27) was amplified from genomic DNA from the cyanobacterium Anabaena strain PCC 7120 and subcloned into pET3a (Novagen) between the BgII and EcoRI sites to create pETazt. A PCR-based quick-change method was employed for simultaneous substitution of Cys19 and Cys22 or Cys120 and Cys123 with Ser using pETazt as a template to create pETazt-C19S/C22S or pETazt-C120S/C123S, respectively. pETaztC19S/C22S/C120S/C123S was prepared in an analogous fashion using pETazt-C19S/C22S as the PCR template. pETazt- $\Delta(1-105)$ was constructed by looping out the coding region for $\mathrm{AztA}^{\mathrm{aH}}$ using a PCR-based quick-change mutagenesis strategy with pETazt as the template. All plasmids were fully sequenced to verify their integrity. pETazt, pETazt-C19S/C22S, pETazt-C120S/C123S, pETazt-C19S/C22S/C120S/C123S, and pETazt- $\Delta(1-105)$ were transformed into E. coli GG48 ( $\triangle$ zitB::Cm $\triangle z n t A:: \mathrm{Km})(30)$ and grown overnight at $37^{\circ} \mathrm{C}$ in LB medium supplemented with $100 \mu \mathrm{g} / \mathrm{mL}$ ampicillin. Cultures were then diluted 1:50 into $10 \mathrm{~mL}$ of fresh $\mathrm{LB} /$ ampicillin medium supplemented with the indicated concentrations of metal salts, and the $\mathrm{OD}_{600}$ was recorded from duplicate or triplicate cultures as a function of time. For the metal concentration dependence, the $\mathrm{OD}_{600}$ was recorded following an 8-10 $\mathrm{h}$ incubation.

\section{Purification of Recombinant AztA ${ }^{\mathrm{aH}}$ and AztA ${ }^{\mathrm{aHbH}}$ from E. coli}

The regions encoding $\mathrm{Azt}^{\mathrm{aH}}$ (residues 1-105) and $\mathrm{Azt}^{\mathrm{aHbH}}{ }^{\mathrm{aHb}}$ (residues 1-213) were amplified by PCR from Anabaena PCC 7120 genomic DNA and cloned into pET3a (Novagen) between $N d e l$ and EcoRI restriction sites to create pET3a-AztA ${ }^{\mathrm{aH}}$ and pET3a$\mathrm{AztA}^{\mathrm{aHbH}}$, respectively. Plasmids encoding C19S/C22S AztA ${ }^{\mathrm{aHbH}}$ and C120S/C123S $\mathrm{AztA}^{\mathrm{aHbH}}$ were constructed from pET3a-AztA ${ }^{\mathrm{aHbH}}$ using PCR-based quick-change mutagenesis. All plasmids were transformed into E. coli BL21(DE3) and grown on LB to midlog phase and induced via addition of $0.4 \mathrm{mM}$ IPTG. Freshly harvested cells were pelleted by low-speed centrifugation and suspended in $100 \mathrm{~mL}$ of buffer A [ $25 \mathrm{mM}$ Tris$\mathrm{HCl}, 3 \mathrm{mM}$ DTT, $1 \mathrm{mM}$ EDTA, and $80 \mathrm{mM}$ imidazole (pH 6.0)] and lysed by sonication. The sonicated supernatant was subjected to HisTrapHP (Amersham Biosciences) chromatography ( $20 \mathrm{~mL}$ bed volume) on anÄkta-10 purifier, with elution achieved with a linear imidazole gradient (from 50 to $400 \mathrm{mM}$ ) in buffer B [25 mM Tris-HCl, $3 \mathrm{mM}$ DTT, and $1 \mathrm{mM}$ EDTA (pH 8.0)]. AztA MBD-containing fractions typically eluted between 125 and $175 \mathrm{mM}$ imidazole, were pooled conservatively, and were further purified using Superdex 75 size-exclusion chromatography (27). Highly purified AztA MBD-containing fractions were pooled, concentrated, and dialyzed against $3 \mathrm{~L}$ of buffer $\mathrm{C}$ [5 mM MES-HCl and $0.20 \mathrm{M} \mathrm{NaCl}(\mathrm{pH}$ 6.5)] in an anaerobic Vacuum Atmospheres glovebox. The purity of 
the final products was estimated by visualization of Coomassie-stained $18 \%$ Tricine-SDSPAGE gels to be $290 \%$. Uniformly ${ }^{15} \mathrm{~N}$-labeled $\mathrm{AztA}^{\mathrm{aH}}$ and $\mathrm{AztA}^{\mathrm{aHbH}}$ were purified in exactly the same way except that cells were grown on an $\mathrm{M} 9$ minimal medium, with $\left({ }^{15} \mathrm{NH}_{4}\right)_{2} \mathrm{SO}_{4}$ as the sole nitrogen source (31). The concentrations of wild-type AztA ${ }^{\mathrm{aHbH}}$, $\mathrm{C} 19 \mathrm{~S} / \mathrm{C} 22 \mathrm{~S}$ (or $\mathrm{C} 120 \mathrm{C} / \mathrm{C} 123 \mathrm{~S}$ ) $\mathrm{Azt}^{\mathrm{aHbH}}$, and $\mathrm{AztA}^{\mathrm{aH}}$ were determined using $\epsilon_{280}$ values of 11 180, 10 930, and 4845 $\mathrm{M}^{-1} \mathrm{~cm}^{-1}$, respectively. All Cys residues in AztA domains were reduced as revealed by an anaerobic DTNB assay (32).

\section{$\mathrm{Cd}(\mathrm{II})$ and $\mathrm{Pb}$ (II) Binding Experiments}

Metal ion binding experiments with $\mathrm{Cd}(\mathrm{II})$ and $\mathrm{Pb}$ (II) were carried out anaerobically at ambient temperature $\left(\approx 25^{\circ} \mathrm{C}\right)$ as described previously (27) in either buffer $\mathrm{C}$ (for $\mathrm{Cd}$ ) or buffer $\mathrm{H}$ [10 $\mathrm{mM}$ bis-Tris and $0.4 \mathrm{M} \mathrm{NaCl}$ (pH 7.0)] (for $\mathrm{Pb}$ ). Metal binding isotherms were fit using DynaFit (33) as described previously (34) to 1:1 binding models with the total concentration of metal binding sites on AztA derivatives being an adjustable parameter.

\section{Zn(II) Binding Experiments}

Mag-fura-2 (Invitrogen M1290) $\left(K_{\mathrm{Zn}}=5.0 \times 10^{7} \mathrm{M}^{-1}\right)(35)$ was employed in a $\mathrm{Zn}$ (II) competition assay with various AztA MBD fragments. Magfura-2 (7-10 $\mu \mathrm{M})$ was mixed anaerobically with a known concentration of apoprotein $(18-20 \mu \mathrm{M})$ in buffer $\mathrm{C}(34)$. The metal concentrations of each titrant were verified by atomic absorption spectroscopy, and the data were fit using a competitive binding model (DynaFit) $(33,34)$ with $K_{\mathrm{Zn}}$ (magfura-2) and [mag-fura-2] as fixed parameters, and the total concentration of $\mathrm{Zn}$ (II) binding sites on AztA derivatives as an adjustable parameter, to account for errors in pipetting, partial inactivation due to cysteine oxidation, or heterogeneity of metal sites. For AztA ${ }^{\mathrm{aHbH}}$, a two-site sequential binding model was used and defined by $K_{\mathrm{Zn} 1}$ and $K_{\mathrm{Zn} 2}$, with the bestfit values of $\left[\mathrm{AztA}^{\mathrm{aHbH}}\right]$ being $19.4 \mu \mathrm{M}\left(20.0 \mu \mathrm{M}\right.$ input). For AztA ${ }^{\mathrm{aH}}$, a 1:1 binding model $\left(K_{\mathrm{Zn}}\right)$ was used with a best-fit [AztA ${ }^{\mathrm{aH}}$ ] of $9.1 \mu \mathrm{M}(18.2 \mu \mathrm{M}$ added). For C19S/C22S $\mathrm{AztA}^{\mathrm{aHbH}}$, a model assuming a mixture of two metal binding species with apparent affinities $K_{\mathrm{Zn}}{ }^{\mathrm{A}}$ and $K_{\mathrm{Zn}}{ }^{\mathrm{B}}$ was used, with best-fit[C19S/C22S AztA $\left.{ }^{\mathrm{aHbH}-\mathrm{A}}\right]$ and[C19S/C22S $\mathrm{AztA}^{\mathrm{aHbH}-\mathrm{B}}$ ] values of $9.9 \mu \mathrm{M}$ each $\left(20.0 \mu \mathrm{M}\right.$ total input), respectively. $K_{\mathrm{Zn}}{ }^{\mathrm{A}}$ reports on a $1: 1$ complex with the $\mathrm{b}-\mathrm{MBD}$, while $K_{\mathrm{Zn}}{ }^{\mathrm{B}}$ likely reports on an intermolecular b- $\mathrm{b}^{\prime}$ bridging species, analogous to the $\mathrm{a}^{-} \mathrm{a}^{\prime}$ bridging species that is observed for $\mathrm{AztA}^{\mathrm{aH}}$ (see Figure $\mathrm{S} 1$ of the Supporting Information).

\section{NMR Spectroscopy}

All NMR spectra were acquired on a Varian Unity Inova $600 \mathrm{MHz}$ spectrometer in the Biomolecular NMR Laboratory at Texas A\&M University. Sample preparation and subsequent metal additions were conducted in an anaerobic Vacuum Atmospheres glovebox at ambient temperature and incubated at least $2 \mathrm{~h}$ before the spectra were recorded. ${ }^{1} \mathrm{H}^{-15} \mathrm{~N}$ HSQC spectra were typically acquired using a $400 \mu \mathrm{M}$ solution of uniformly ${ }^{15} \mathrm{~N}$-labeled $\mathrm{AztA}^{\mathrm{aHbH}}$ or $\mathrm{AztA}^{\mathrm{aH}}$ in buffer $\mathrm{C}[5 \mathrm{mM}$ Mes and $0.20 \mathrm{M} \mathrm{NaCl}(\mathrm{pH} 6.5)]$ at $25^{\circ} \mathrm{C}$. Sequential ${ }^{1} \mathrm{H}_{\mathrm{N}},{ }^{15} \mathrm{~N},{ }^{13} \mathrm{Ca}$, and ${ }^{13} \mathrm{C} \beta$ resonance assignments of the a-MBD region were obtained using a $0.35 \mathrm{mM}$ uniformly ${ }^{15} \mathrm{~N}$ - and ${ }^{13} \mathrm{C}$-labeled apo-AztA ${ }^{\mathrm{aH}}$ sample from analysis of ${ }^{1} \mathrm{H}-{ }^{15} \mathrm{~N}$ HSQC, CBCA-(CO)NH, and HNCACB experiments in buffer $\mathrm{C}$ containing $90 \% \mathrm{H}_{2} \mathrm{O}$ and $10 \% \mathrm{D}_{2} \mathrm{O}$. NMR data were processed using NMRPipe and analyzed using Sparky, essentially as previously described (31). PREDICTOR (36) was used to analyze backbone ${ }^{1} \mathrm{H}_{\mathrm{N}},{ }^{15} \mathrm{~N},{ }^{13} \mathrm{Ca}$ and ${ }^{13} \mathrm{C} \beta$ chemical shifts and sequence analysis to define the secondary structural segments in $\mathrm{AztA}^{\mathrm{aH}}$. The torsion angles ( $\Psi, \Phi$, and $\left.\chi_{1}\right)$ of $\mathrm{AztA}^{\mathrm{aH}}$ predicted by PREDICTOR were found to be comparable to those experimentally determined in Bacillus subtilis CopZ (37). 


\section{NMR Analysis of Mixtures of $\left[{ }^{15} \mathrm{~N}\right] \mathrm{Azt} \mathrm{A}^{\mathrm{aH}}$ and Unlabeled C19S/C22S AztA ${ }^{\mathrm{aHbH}}$}

$\mathrm{Zn}_{1}$-bound ${ }^{15} \mathrm{~N}$-labeled $\mathrm{AztA}^{\mathrm{aH}}(0.4 \mathrm{mM})$ incubated for $12 \mathrm{~h}$ in an anaerobic chamber was mixed with unlabeled $\mathrm{C} 19 \mathrm{~S} / \mathrm{C} 22 \mathrm{~S} \mathrm{AztA}{ }^{\mathrm{aHbH}}$ at molar ratios of $1: 1$ and $1: 1.5$, and ${ }^{1} \mathrm{H}-{ }^{15} \mathrm{~N}$ HSQC spectra were recorded within $2 \mathrm{~h}$ as described above.

\section{X-ray Absorption Spectroscopy of $\mathrm{Zn}-$ and Cd-AztA ${ }^{\text {aH }}$ Complexes}

Samples of $\approx 1 \mathrm{mM} \mathrm{AztA}^{\mathrm{aH}}$ containing 0.7 molar equiv of $\mathrm{Zn}$ (II) or 0.5 molar equiv of Cd(II) were loaded into $10 \mu \mathrm{L}$ wells of Lexan cuvets with 0.001 in. thick Kapton windows. $\mathrm{Zn}$ and Cd K edge X-ray absorption spectroscopic data were collected at the Stanford Synchrotron Radiation Laboratory on beamline 9-3 with the SPEAR3 ring operating at 3.0 $\mathrm{GeV}$ and $85-100 \mathrm{~mA}$, with a fully tuned $\mathrm{Si}$ (220) $\mathrm{LN}_{2}$-cooled monochromator, using a vertical aperture of $1 \mathrm{~mm}$, and the upstream mirror set for harmonic rejection. Fluorescence excitation spectra were collected using a 30-element intrinsic Ge detector (Canberra) windowed to either $\mathrm{Zn}$ or $\mathrm{Cd} \mathrm{Ka}$ emission. For $\mathrm{Zn}$, a $6 \mu \mathrm{m} \mathrm{Cu}$ fluorescence filter backed by Soller slits was employed. The spectra shown in Figure 5 were averaged from six ( $\mathrm{Zn}$ ) and three $(\mathrm{Cd}) 21$ min scans, and the data were reduced and analyzed using EXAFSPAK (http:// www-ssrl.slac.stanford.edu/exafspak.html). Internal energy calibration defined the first inflection of $\mathrm{Zn}$ and $\mathrm{Cd}$ elemental standards as 9660.7 and $26714.0 \mathrm{eV}$, respectively. $k$ values were calculated using threshold $(k=0)$ energies of 9670 and $26720 \mathrm{eV}$, respectively.

\section{RESULTS}

\section{The a- and b-MBDs Play Functionally Nonequivalent Roles in Zinc Resistance in E. coli}

Previous studies of metal-sensing cyanobacterial operons regulated by ArsR family repressors suggest that these operons function similarly in E. coli and their original cyanobacterial hosts $(27,38,39)$. To evaluate the degree to which individual MBDs are required to confer metal resistance in cell culture, we transformed the well-characterized $\mathrm{Zn} /$ $\mathrm{Pb} / \mathrm{Cd}$ hypersensitive strain $E$. coli GG48 ( $\triangle$ zitB, $\Delta z n t A)(30)$, which lacks both known low- and high-affinity $\mathrm{Zn} / \mathrm{Cd}$ efflux systems, with plasmids encoding the complete Anabaena azt operon in which one MBD or the other was inactivated by mutation. Figure $2 \mathrm{~A}$ reveals that $E$. coli $\mathrm{GG} 48$ transformed with an azt operon in which the a-MBD was inactivated $(\mathrm{C} 19 \mathrm{~S} / \mathrm{C} 22 \mathrm{~S}$ azt $)$ is more sensitive to zinc toxicity at long incubation times (8-10 h) relative to GG48 transformed with an azt operon in which the b-MBD was inactivated (C120S/C123S azt). Analysis of the full growth curves for these strains measured in the presence of an intermediate concentration of $\mathrm{Zn}$ (II) $(200 \mu \mathrm{M})$ reveals that this differential effect manifests itself at long incubation times (Figure 2C). In contrast, growth curves measured at highly toxic levels of $\mathrm{Zn}$ (II) ( $2500 \mu \mathrm{M}$ ) (Figure 2E) reveal that while the bMBD mutant retains a level of zinc resistance just below that of the wild-type operon, inactivation of the a-MBD confers a level of resistance only just above that of nontransformed cells. A similar level of resistance is obtained when both the a- and b-MBDs are inactivated compared to the a-MBD alone; this suggests that the a-MBD is largely capable of functioning independently of the b-MBD at high intracellular zinc loads. Unlike the case with $\mathrm{Zn}(\mathrm{II})$, inactivation of either the a- or the b-MBDs has only a small, but roughly equivalent, influence on $\mathrm{Cd}(\mathrm{II})$ resistance relative to the wild-type azt operon, with the double mutant only slightly more sensitive to high Cd(II) loads $(25 \mu \mathrm{M})$ with long incubation times (Figure 2B,D,F). Thus, the presence of at least one functional MBD is sufficient to confer nearly wild-type, albeit modest (27), levels of Cd(II) resistance in these cells, a situation that appears to contrast with that of $\mathrm{Zn}(\mathrm{II})$. 


\section{The Two MBDs of AztA Have Different Zn(II) Binding Affinities}

The in vivo metal resistance experiments described above make the prediction that individual MBDs might have distinct Zn(II) binding properties and that complexes formed with $\mathrm{Zn}$ (II) might be structurally different from those formed by $\mathrm{Cd}(\mathrm{II})$ and $\mathrm{Pb}$ (II). We first determined the stoichiometry and affinity of $\mathrm{Zn}$ (II) binding to various MBD-containing AztAs using a metal chelator competition assay. Here, the $\mathrm{Zn}$ (II) chelator mag-fura-2 (34) with a $K_{\mathrm{Zn}}$ of $5.010^{7} \mathrm{M}^{-1}$ (35) is mixed with purified AztA MBD-containing fragments and titrated with $\mathrm{Zn}$ (II) in an anaerobic atmosphere. The binding of $\mathrm{Zn}$ (II) to mag-fura-2 leads to a shift in the absorption maximum (from 366 to $325 \mathrm{~nm}$ ). As shown in Figure 3A, the total concentration of $\mathrm{Zn}(\mathrm{II})$ required to saturate $\mathrm{AztA}^{\mathrm{aHbH}}(20 \mu \mathrm{M})$ and mag-fura-2 $(9.7 \mu \mathrm{M})$ is $\approx 50 \mu \mathrm{M}$. This experiment reveals that $\mathrm{AztA}^{\mathrm{aHbH}}$ binds 2 molar equiv of $\mathrm{Zn}$ (II) with a $K_{\mathrm{Zn}}$ of $\geq 10^{5} \mathrm{M}^{-1}$. Quantitative curve fitting to a two-site binding model reveals that one $\mathrm{Zn}(\mathrm{II})$ binds to AztA ${ }^{\mathrm{aHbH}}$ with an affinity far greater than that of mag-fura- $2\left[K_{\mathrm{Zn} 1}=(9.4 \pm 1.0) \times\right.$ $10^{8} \mathrm{M}^{-1}$ ], while the second binds with an affinity only slightly greater than that of magfura-2 $\left.\left[K_{\mathrm{Zn} 2}=8.0 \pm 0.6\right) \times 10^{7} \mathrm{M}^{-1}\right]$. The simplest interpretation of this experiments is that each MBD of Azt ${ }^{\mathrm{aHbH}}$ binds 1 molar equiv of $\mathrm{Zn}$ (II) with measurably different affinities. If the His-rich linker segments in $\mathrm{AztA}^{\mathrm{aHbH}}$ bind $\mathrm{Zn}$ (II), these sites are characterized by an affinity $K_{\mathrm{Zn}}$ of $\leq 10^{5} \mathrm{M}^{-1}$ or far weaker than that of magfura-2, since they are not observed in this assay.

To determine which MBD (a or b) binds Zn(II) more tightly, we performed parallel competition experiments with $\mathrm{AztA}^{\mathrm{aH}}$ (Figure $3 \mathrm{~B}$ ), which contains only the a-MBD and the His-rich region, and C19S/C22S AztA ${ }^{\mathrm{aHbH}}$ (Figure 3C), which contains a wild-type b-MBD and both His-rich domains. As one can see, the added $\mathrm{Zn}(\mathrm{II})$ binds to $\mathrm{AztA}^{\mathrm{aH}}$ and magfura-2 with approximately equal affinity until saturation of the available sites occurs, with a $K_{\mathrm{Zn}}$ of $(9.3 \pm 1.5) \times 10^{7} \mathrm{M}^{-1}$, or comparable to that of the low-affinity binding site in intact $\mathrm{AztA}^{\mathrm{aHbH}}$ (Figure 3B). In contrast, there is a clear plateau in the early region of the titration curve for C19S/C22S AztA ${ }^{\mathrm{aHbH}}$ (Figure 3C) like that for intact AztA ${ }^{\mathrm{aHbH}}$, with a $K_{\mathrm{Zn}}$ of $(8.4 \pm 2.8) \times 10^{8} \mathrm{M}^{-1}$ or comparable to that of the high-affinity site in wild-type $\mathrm{AztA}^{\mathrm{aHbH}}$ (Figure 3A). These data reveal that each of the two MBDs of AztA ${ }^{\mathrm{aHbH}}$ harbors a $\mathrm{Zn}$ (II) binding site and that the affinity of $\mathrm{Zn}$ (II) for the N-terminal a-MBD is lower by a factor of 5-10 than that for the C-terminal b-MBD.

\section{$\mathrm{Cd}(\mathrm{II})$ and $\mathrm{Pb}$ (II) Form Inter- and Intramolecularly Bridging Structures}

Cd(II) was shown to be a strong inducer of aztA expression in Anabaena but confers little resistance to Cd(II) salts in E. coli (27). The UV-visible absorption spectra of AztA ${ }^{\mathrm{aHbH}}$ titrated with $\mathrm{Cd}(\mathrm{II})$ show the formation of a stoichiometric $1: 1 \mathrm{Cd}(\mathrm{II})-\mathrm{AztA}^{\mathrm{aHbH}}$ complex (Figure 4A, inset), in contrast to that obtained with Zn(II) (Figure 3). The intense absorption at $\approx 240 \mathrm{~nm}$ can be attributed to $\mathrm{S}^{-} \rightarrow \mathrm{Cd}$ (II) ligand-to-metal charge transfer transitions with an $\epsilon_{240}$ of $\approx 5000-6000 \mathrm{M}^{-1} \mathrm{~cm}^{-1}$ expected per $\mathrm{Cd}-\mathrm{S}$ bond $(40,41)$. The molar absorptivity of the 1:1 Cd(II)-AztA ${ }^{\mathrm{aHbH}}$ complex is $19000 \mathrm{M}_{\mathrm{Cd}}^{-1} \mathrm{~cm}^{-1}$ (Figure 4A), a value consistent with three to four cysteine thiolate ligands. This result suggests that a single $\mathrm{Cd}(\mathrm{II})$ ion bridges both MBDs in intact $\mathrm{AztA}^{\mathrm{aHbH}}$, an interpretation supported by sedimentation equilibrium experiments (see below).

In contrast, the single a-MBD-containing $\mathrm{AztA}^{\mathrm{aH}}$ binds only 0.5 molar equiv of $\mathrm{Cd}(\mathrm{II})$ at

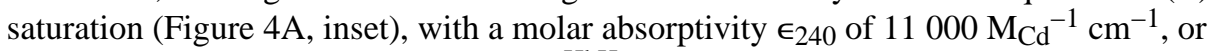
approximately one-half of that of $\mathrm{AztA}^{\mathrm{aHbH}}$; this suggests that a single $\mathrm{Cd}(\mathrm{II})$ ion forms an intermolecular $\mathrm{S}_{4}$ complex between two AztA ${ }^{\mathrm{aH}}$ domains. The same stoichiometry and molar absorptivity characterize the $\mathrm{C} 19 \mathrm{~S} / \mathrm{C} 22 \mathrm{~S}$ AztA ${ }^{\mathrm{aHbH}}$ complex (Figure 4A). Similar trends are observed for $\mathrm{Pb}$ (II) (Figure 4B). Two $\mathrm{S}^{-} \rightarrow \mathrm{Pb}$ (II) LMCT transitions are observed for $\mathrm{Pb}$ (II)-saturated $\mathrm{Azt}_{\mathrm{A}}{ }^{\mathrm{aHbH}}$ with the molar absorptivities and energies of these absorption 
bands most consistent with approximately three thiolate ligands to the $\mathrm{Pb}(\mathrm{II})$ ion $(27,42-$ 44).

The assembly states of $\mathrm{Zn}_{1^{-}}, \mathrm{Zn}_{2^{-}}, \mathrm{Cd}_{1^{-}}$, and $\mathrm{Pb}_{1^{-}}$-substituted $\mathrm{AztA}^{\mathrm{aHbH}}$ are all described well by a single-ideal species molecular mass of $\approx 24 \mathrm{kDa}$ in all cases, consistent with monomeric AztA ${ }^{\mathrm{aHbH}}$ (Table SI of the Supporting Information). Thus, the Cys-thiolate-rich $\mathrm{Cd}_{1}$ and $\mathrm{Pb}_{1}$ complexes are best described as intramolecularly bridging chelates that crosslink the a- and b-MBDs. In contrast, size exclusion chromatography analysis of apo versus $\mathrm{Zn}_{1}$ and $\mathrm{Cd}_{0.5}$ forms of $\mathrm{AztA}^{\mathrm{aH}}$ (Figure S1) reveals that while the apparent molecular masses of apo-AztA ${ }^{\mathrm{aH}}$ and $\mathrm{Zn}_{1}$-bound $\mathrm{AztA}^{\mathrm{aH}}$ are mostly monomeric $(\approx 12 \mathrm{kDa})$, addition of 0.5 molar equiv of $\mathrm{Cd}(\mathrm{II})$ gives rise to an $\approx 23 \mathrm{kDa}$ dimeric species. These results are consistent with parallel dynamic light scattering experiments (Figure S1). Thus, Cd(II) readily mediates intermolecular a-a' cross-linking of a-MBDs between $\mathrm{AztA}^{\mathrm{aH}}$ molecules, in contrast to $\mathrm{Zn}(\mathrm{II})$.

\section{X-ray Absorption Spectroscopy of Zn(II)- and Cd(II)-Bound AztA ${ }^{\text {aH }}$}

K-Edge X-ray absorption spectroscopy (XAS) was employed to further investigate the $\mathrm{Zn}$ (II) and Cd(II) metal-ligand donor sets. Cd K-edge X-ray absorption spectroscopic analysis of the $\mathrm{Cd}(\mathrm{II})-\mathrm{Azt}^{\mathrm{aH}}$ complex indicates a coordination environment consisting primarily of sulfur scatterers at $2.50 \AA$ (Figure 5A). The data are most consistent with an average $\mathrm{Cd}(\mathrm{II}) \mathrm{S}_{3}(\mathrm{O} / \mathrm{N})$ coordination complex (Table SII of the Supporting Information). In contrast, curve fitting of EXAFS obtained for equilibrium $\mathrm{Zn}(\mathrm{II})_{0.7}-\mathrm{AztA}^{\mathrm{aH}}$ complexes reveals a $\mathrm{Zn}(\mathrm{II}) \mathrm{S}_{2}(\mathrm{~N} / \mathrm{O})_{2}$ coordination environment, a finding consistent with coordination by Cys 19 and Cys22 and possibly Asp18, as reported in E. coli ZntA (19), with a water molecule completing the tetrahedral chelate structure (Figure 5B and Table SII).

\section{NMR Studies of $\mathrm{Zn}(\mathrm{II})-, \mathrm{Cd}(\mathrm{II})-$, and $\mathrm{Pb}$ (II)-Bound AztA $\mathrm{A}^{\mathrm{aHbH}}$}

Since $\mathrm{Zn}(\mathrm{II})$ and $\mathrm{Cd}(\mathrm{II}) / \mathrm{Pb}(\mathrm{II})$ bind to $\mathrm{AztA}^{\mathrm{aHbH}}$ with different stoichiometries and coordination structures, we next examined the nature of the structural changes by NMR spectroscopy in an attempt to correlate these changes to the specificity of metal transport by AztA. We recorded two-dimensional $1 \mathrm{H}-{ }^{15} \mathrm{~N}$ HSQC spectra of AztA ${ }^{\mathrm{aHbH}}$ in the absence and presence of 1 and 2 molar equiv of $\mathrm{Zn}$ (II) versus saturating $1: 1 \mathrm{Cd}$ (II) and $\mathrm{Pb}$ (II) and compared these spectra to those of apo and $\mathrm{Zn}_{1}$-bound $\mathrm{AztA}^{\mathrm{aH}}$ (Figure 6). Inspection of the ${ }^{1} \mathrm{H}-{ }^{15} \mathrm{~N}$ HSQC spectra acquired for apo-AztA ${ }^{\mathrm{aHbH}}$ (Figure $6 \mathrm{~B}$ ) versus those for apo$\mathrm{AztA}^{\mathrm{aH}}$ (Figure 6A, blue contours) reveals that of the two MBDs of AztA ${ }^{\mathrm{aHbH}}$, only the Nterminal a-MBD gives well-resolved resonances of relatively uniform intensity; in contrast, the expected resonances for the C-terminal b-MBD are of significantly lower intensity and, in some cases, missing altogether (Figure S2 of the Supporting Information). Intermediate (microsecond to millisecond) exchange on the ${ }^{1} \mathrm{H}$ NMR time scale between two or more conformations seems a likely origin of resonance broadening, a characteristic not unprecedented from NMR studies of other Atx1-like MBDs (45).

Complete ${ }^{1} \mathrm{H}_{\mathrm{N}}$ and ${ }^{15} \mathrm{~N},{ }^{13} \mathrm{Ca}$, and ${ }^{13} \mathrm{C} \beta$ assignments were obtained for apo-AztA ${ }^{\mathrm{aH}}$ from Ser6 to Gln75, with the exception of Leu30, and Asp18, Cys19, and Ser21 in the metal binding loop (Table SIII of the Supporting Information). A comparison of the amide chemical shifts of the a-MBD in the context of $\mathrm{AztA}^{\mathrm{aH}}$ versus $\mathrm{AztA}^{\mathrm{aHbH}}$ shows that they are virtually identical in the apo state (Figures $\mathrm{S} 2$ and $\mathrm{S} 3$ ), consistent with little interaction between the a- and b-MBDs in the two-domain $\mathrm{AztA}^{\mathrm{aHbH}}$ molecule. Chemical shift indexing using PREDICTOR (36) is consistent with the expected $\beta a \beta \beta a \beta$ topology (10), with secondary structural segments encompassing approximately residues $7-15(\beta 1), 22-31$ $(a 1), 37-42$ ( $\beta 2), 47-53$ ( $\beta 3$ ), 59-67 (a2), and 71-74 ( $\beta 4$ ) (see Figure 1B). Binding of $\mathrm{Zn}(\mathrm{II})$ to $\mathrm{AztA}^{\mathrm{aH}}$ induces significant chemical shift perturbations in the metal binding loop 
region, flanking residues in the $\beta 1$ strand and a 1 helix, and the $\beta 2-\beta 3$ loop in the proximity of the metal binding loop (Figure 6A and Figure S3). In the spectral region that is shown, Val14, Cys22, and Ile26 in the metal binding loop and Val41 and Ala48 in the $\beta 2-\beta 3$ loop region are good reporters of metal binding by the a-MBD.

A comparison of the changes in the spectra of apo- $\mathrm{Azt} \mathrm{A}^{\mathrm{aHbH}}$ upon addition of 1 (red contours) versus 2 (green contours) molar equiv of $\mathrm{Zn}$ (II) reveals that the addition of the first molar equivalent of $\mathrm{Zn}$ (II) induces very little perturbation in the amide groups of the aMBD, consistent with the relative affinities of the two MBDs for Zn(II) (Figure 3). Upon addition of the second molar equivalent of $\mathrm{Zn}$ (II), we see significant perturbations in the aMBD within AztA ${ }^{\mathrm{aHbH}}$ (Figure 6B), analogous to those changes observed upon addition of $\mathrm{Zn}$ (II) to $\mathrm{AztA}^{\mathrm{aH}}$ (Figure 6A). In contrast, addition of a stoichiometric amount of $\mathrm{Cd}(\mathrm{II})$ (Figure 6D) or $\mathrm{Pb}(\mathrm{II}$ ) (Figure 6C) induces perturbations of the a-MBD resonances qualitatively analogous to those observed upon addition of $\mathrm{Zn}(\mathrm{II})$ to $\mathrm{Azt}^{\mathrm{aH}}$, with Cys22, Ile26, and Val41 reporting most strongly on these changes (Figure 6A). Note that these spectral changes do not allow us to easily discriminate between monomolecular a-MBD and interdo-main a-b MBD metal-cross-linked species since we can observe changes in only aMBD resonances. Nonetheless, these data are consistent with formation of an a-MBD-bMBD site-bridging complex in $\mathrm{Cd}_{1}-$ and $\mathrm{Pb}_{1}-\mathrm{Azt}^{\mathrm{aHbH}}$ complexes that is structurally distinct from that in the $\mathrm{Zn}_{1}$ and $\mathrm{Zn}_{2}$ complexes.

\section{Facile Transfer of $\mathrm{Zn}(\mathrm{II})$ from the a-MBD to the b-MBD}

Since the b-MBD has a higher equilibrium affinity for $\mathrm{Zn}$-(II) relative to the $\mathrm{N}$-terminal aMBD, this finding makes the prediction that $\mathrm{Zn}(\mathrm{II})$ bound to the a-MBD should be capable of transferring to the b-MBD on thermodynamic grounds, provided the energy barrier between the two states is small. To test this idea, we incubated $\mathrm{Zn}$ (II)-complexed, ${ }^{15} \mathrm{~N}$ labeled $\mathrm{AztA}^{\mathrm{aH}}$ (red contours) with unlabeled apo-C19S/C22S AztA ${ }^{\mathrm{aHbH}}$ at a ratio of 1:1 (blue contours) and monitored metal occupancy of the a-MBD by ${ }^{1} \mathrm{H}-{ }^{15} \mathrm{~N}$ HSQC spectroscopy (Figure 7). These data show that the apo b-MBD is capable of stripping the $\mathrm{Zn}$ (II) prebound to the a-MBD, given the appearance of apo state resonance frequencies for Cys22, Ile26, and Val41 in ${ }^{15} \mathrm{~N}$-labeled AztA ${ }^{\mathrm{aH}}$, among others. The transfer efficiency estimated by the relative peak intensities of $\mathrm{Zn}$ (II) versus apo state cross-peaks for Val41 suggests that $280 \%$ of the $\mathrm{Zn}$ (II) moved from the a-MBD in AztA ${ }^{\text {aH }}$ to the b-MBD in C19S/ $\mathrm{C} 22 \mathrm{~S} \mathrm{AztA}{ }^{\mathrm{aHbH}}$ under these conditions, a finding roughly consistent with their relative affinities.

\section{DISCUSSION}

How N-terminal MBDs influence metal transport by the divalent metal ion-specific $\mathrm{P}_{1 \mathrm{~B}}$-type ATPases is not fully understood. In simple $\mathrm{Zn} / \mathrm{Cd} / \mathrm{Pb}$-specific $\mathrm{P}_{1 \mathrm{~B}}$-type ATPases, e.g., $E$. coli ZntA, kinetic studies reveal that the single $\mathrm{N}$-terminal MBD enhances the steady state ATPase activity (46) and overall turnover of the enzyme, either by increasing the rate of metal binding, which is fast $\left(\approx 10^{8} \mathrm{M}^{-1} \mathrm{~s}^{-1}\right)$ (47), or by stimulating the release of metal ion from the transmembrane site, which is rate-limiting for transport (17). Our studies with Anabaena AztA provide new insights into how tandemly linked MBDs in a divalent metal transporter might bias the metal specificity of the efflux pump more toward $\mathrm{Zn}$ (II), relative to abiological $\mathrm{Cd}(\mathrm{II})$ and $\mathrm{Pb}$ (II) ions, in a way that is not achievable with a single MBD. They further suggest that the trend toward increasing numbers of MBDs found in mammalian copper-specific transporters might have been used to fine-tune the intrinsic metal selectivity and transport efficiency of the pump beyond that which was possible with no or one MBD. 
Consistent with previous studies, neither MBD is absolutely essential for mediating metal resistance and, by extension, metal efflux through the AztA transporter (48). However, they do suggest that the low-affinity a-MBD serves a specialized regulatory role under high intracellular zinc loads in a manner that appears to be largely independent of the b-MBD (Figure 2). Perhaps only under these conditions would the low-affinity N-terminal a-MBD be capable of binding $\mathrm{Zn}$ (II) in the cell, which would then quickly move via simple mass action (dissociation and/or reassociation) or direct transfer via metal-ligand exchange to the membrane proximal b-MBD (Figure 7) or the transmembrane site itself (see Figure 8A) on thermodynamic grounds, given the higher affinity of each for $\mathrm{Zn}$ (II) relative to the a-MBD (Figure 3) (49). However, it is important to emphasize that it has not yet been shown that $\mathrm{Zn}(\mathrm{II})$ is capable of moving from the a-MBD to either site directly within the same polypeptide chain, nor has the affinity of the transmembrane site for $\mathrm{Zn}(\mathrm{II})$ in AztA been experimentally determined. Although inter-MBD copper transfer has also been observed among the MBDs in ATP7B, as well as intermolecular transfer between Hah1 and select MBDs in both ATP7A and ATP7B $(12,50,51)$, our data do not support a model of an obligatory transfer from the a-MBD to the b-MBD since inactivation of the b-MBD alone mediates a level of $\mathrm{Zn}$ (II) resistance that is nearly as effective as that of the wild-type MBD.

In contrast to the situation with $\mathrm{Zn}$ (II), the more thiophilic $\mathrm{Cd}(\mathrm{II})$ and $\mathrm{Pb}$ (II) ions appear to form kinetically stable inter- and intramolecularly bridged metal complexes in AztA (Figures 3-5), analogous to those observed previously for Cd(II)-bound CadA from $L$. monocytogenes (20) and metalated copper chaperones $(14,25,52)$ (Figure 8B). Furthermore, this intramolecularly bridged metal complex in $\mathrm{AztA}^{\mathrm{aHbH}}$ may be electrostatically stabilized as well, due to the anticipated complementary surface potentials of the a- and b-MBDs, with the a-MBD characterized by a small positive patch contributed by the $\beta 3$ strand with the b-MBD exhibiting a strongly negative surface potential on the a3$\beta 4$ face of the domain (Figure S5 of the Supporting Information). The Cd(II) and $\mathrm{Pb}(\mathrm{II})$ complexes thus formed may not be a strong allosteric modulator of the ATPase activity relative to the $\mathrm{Zn}$ (II) complex, thus providing a means of biasing the metal selectivity of the efflux pump toward $\mathrm{Zn}(\mathrm{II})$.

Anabaena AztA, like the closely related Synechocystis ZiaA (53), likely transports Zn(II) from the cytoplasm to the periplasm. The periplasm is known to be important for metal ion partitioning and homeostasis, and this is particularly so for cyanobacteria which have unusual requirements for iron, copper, and manganese to supply the photosynthetic machinery with metal cofactors, as well as for other metal ions such as Zn, Co, and Mo (54). This compartment contains several metal-specific solute binding proteins, including Synechocystis ZnuA (Zn-specific) (55) and FutA2 (Fe ${ }^{\mathrm{III}}$-specific) (56) and Anabaena AzuA (likely Zn-specific) (27) that could function in metal storage and homeostasis of essential transition ions, and at high intracellular loads, in detoxification. Anabaena, like other cyanobacteria such as Oscillatoria brevis (57) and Synechococcus (58), is known to encode a metallothionein that efficiently sequesters divalent metals in the cytoplasm (59). Cd binds to Synechococcus SmtA avidly and is readily capable of displacing three of its four bound $\mathrm{Zn}$ ions (60). Anabaena and other cyanobacteria may have evolved partially overlapping or redundant detoxification and storage systems for zinc in a manner that maintains an optimal response to abiological $\mathrm{Cd}$ and $\mathrm{Pb}$.

Finally, although similar His-rich sequences have been identified in other $\mathrm{Zn} / \mathrm{Cd}$-specific $\mathrm{P}_{1 \mathrm{~B}}$-type ATPases $(53,57)$, the functional role of these regions C-terminal to both the a- and b-MBDs in AztA requires further study. Blast analysis against the complete plant and bacterial genome databases suggests that an AztA-like domain organization of a canonical MBD followed by a His-rich segment in predicted metal-transporting ATPases is not unique and can be found in most classes of bacteria, including Proteobacteria, Firmicutes, 
Bacteroidetes, and Cyanobacteria, in addition to Arabidopsis. Clearly, the His-rich region between residue $\approx 77$ and 105 in $\mathrm{Azt}^{\mathrm{aH}}$ is unstructured and/or conformationally dynamic since sequential assignments for most of these resonances could not be obtained due to resonance overlap or conformation exchange broadening (Figure S4). However, addition of a stoichiometric amount of $\mathrm{Zn}$ (II) to $\mathrm{AztA}^{\mathrm{aH}}$ results in movement and chemical exchange broadening of at least a subset of these resonances which is largely paralleled by chemical shift perturbations in the metal binding and $\beta 2-\beta 3$ loops within the folded domain (Figure 6). The simplest interpretation of these spectral changes is that the bound $\mathrm{Zn}$ (II) is in intermediate exchange between sites, despite the fact that the His-rich linker binds Zn(II) with an apparent affinity that is weaker than even that of the a-MBD, since mutagenesis of the Cys pair in individual MBDs abrogates high-affinity $\left(K_{\mathrm{Zn}} \geq 5 \times 10^{5} \mathrm{M}^{-1}\right)$ metal binding (Figure 3). Binding of metal to these His-rich domains may enhance the on-rate and/or facilitate the transfer of metal between MBDs and the b-MBD and intramembrane sites. Consistent with this, preliminary findings reveal that incubation with antisera raised against the His-rich sequence in Bxa1, a closely related CPx-ATPase from the cyanobacterium $O$. brevis (39), significantly decreases the ATPase activity of Bxa1 in vitro (T. Liu, unpublished results). Detailed kinetic studies of metal binding will be required to understand the mechanistic role that these domains play in stimulation of ATPase activity and metal transport across membranes.

\section{Supplementary Material}

Refer to Web version on PubMed Central for supplementary material.

\section{Acknowledgments}

We thank Dr. Xiangming Kong for help in acquiring the NMR data, Dr. Xiaohua Chen and Mr. Zhen Ma for assistance in analyzing the metal titration data, and Dr. Xiaohua Chen for constructing plasmids used in this work.

\section{REFERENCES}

1. Lutsenko S, Kaplan JH. Organization of P-type ATPases: Significance of structural diversity. Biochemistry. 1995; 34:15607-15613. [PubMed: 7495787]

2. Arguello JM. Identification of ion-selectivity determinants in heavy-metal transport $\mathrm{P}_{1 \mathrm{~B}}$-type ATPases. J. Membr. Biol. 2003; 195:93-108. [PubMed: 14692449]

3. Arnesano F, Banci L, Bertini I, Ciofi-Baffoni S, Molteni E, Huffman DL, O'Halloran TV. Metallochaperones and metal-transporting ATPases: A comparative analysis of sequences and structures. Genome Res. 2002; 12:255-271. [PubMed: 11827945]

4. Bartee MY, Lutsenko S. Hepatic copper-transporting ATPase ATP7B: Function and inactivation at the molecular and cellular level. Biometals. 2007; 20:627-637. [PubMed: 17268820]

5. Williams LE, Mills RF. P(1B)-ATPases: An ancient family of transition metal pumps with diverse functions in plants. Trends Plant Sci. 2005; 10:491-502. [PubMed: 16154798]

6. Dutta SJ, Liu J, Hou Z, Mitra B. Conserved aspartic acid 714 in transmembrane segment 8 of the ZntA subgroup of P1B-type ATPases is a metal-binding residue. Biochemistry. 2006; 45:59235931. [PubMed: 16669635]

7. Sazinsky MH, Agarwal S, Arguello JM, Rosenzweig AC. Structure of the Actuator Domain from the Archaeoglobus fulgidus $\mathrm{Cu}^{+}$-ATPase. Biochemistry. 2006; 45:9949-9955. [PubMed: 16906753]

8. Sazinsky MH, Mandal AK, Arguello JM, Rosenzweig AC. Structure of the ATP binding domain from the Archaeoglobus fulgidus $\mathrm{Cu}^{+}$-ATPase. J. Biol. Chem. 2006; 281:11161-11166. [PubMed: 16495228]

9. Dmitriev O, Tsivkovskii R, Abildgaard F, Morgan CT, Markley JL, Lutsenko S. Solution structure of the N-domain of Wilson disease protein: Distinct nucleotide-binding environment and effects of disease mutations. Proc. Natl. Acad. Sci. U.S.A. 2006; 103:5302-5307. [PubMed: 16567646] 
10. Rosenzweig AC, O'Halloran TV. Structure and chemistry of the copper chaperone proteins. Curr. Opin. Chem. Biol. 2000; 4:140-147. [PubMed: 10742187]

11. Walker JM, Huster D, Ralle M, Morgan CT, Blackburn NJ, Lutsenko S. The N-terminal metalbinding site 2 of the Wilson's Disease Protein plays a key role in the transfer of copper from Atox1. J. Biol. Chem. 2004; 279:15376-15384. [PubMed: 14754885]

12. Achila D, Banci L, Bertini I, Bunce J, Ciofi-Baffoni S, Huffman DL. Structure of human Wilson protein domains 5 and 6 and their interplay with domain 4 and the copper chaperone HAH1 in copper uptake. Proc. Natl. Acad. Sci. U.S.A. 2006; 103:5729-5734. [PubMed: 16571664]

13. Banci L, Bertini I, Cantini F, Felli IC, Gonnelli L, Hadjiliadis N, Pierattelli R, Rosato A, Voulgaris P. The Atx1-Ccc2 complex is a metal-mediated protein-protein interaction. Nat. Chem. Biol. 2006; 2:367-368. [PubMed: 16732294]

14. Banci L, Bertini I, Ciofi-Baffoni S, Kandias NG, Robinson NJ, Spyroulias GA, Su XC, Tottey S, Vanarotti M. The delivery of copper for thylakoid import observed by NMR. Proc. Natl. Acad. Sci. U.S.A. 2006; 103:8320-8325. [PubMed: 16707580]

15. Pufahl RA, Singer CP, Peariso KL, Lin SJ, Schmidt PJ, Fahrni CJ, Culotta VC, Penner-Hahn JE, O'Halloran TV. Metal ion chaperone function of the soluble $\mathrm{Cu}(\mathrm{I})$ receptor Atx1. Science. 1997; 278:853-856. [PubMed: 9346482]

16. Rae TD, Schmidt PJ, Pufahl RA, Culotta VC, O'Halloran TV. Undetectable intracellular free copper: The requirement of a copper chaperone for superoxide dismutase. Science. 1999; 284:805-808. [PubMed: 10221913]

17. Mandal AK, Arguello JM. Functional roles of metal binding domains of the Archaeoglobus fulgidus $\mathrm{Cu}^{+}$-ATPase CopA. Biochemistry. 2003; 42:11040-11047. [PubMed: 12974640]

18. Borrelly GP, Rondet SA, Tottey S, Robinsn NJ. Chimeras of P-type ATPases and their transcriptional regulators: Contributions of a cytosolic amino-terminal domain to metal specificity. Mol. Microbiol. 2004; 53:217-227. [PubMed: 15225316]

19. Banci L, Bertini I, Ciofi-Baffoni S, Finney LA, Outten CE, O'Halloran TV. A new zinc-protein coordination site in intracellular metal trafficking: Solution structure of the Apo and $\mathrm{Zn}$ (II) forms of ZntA(46-118). J. Mol. Biol. 2002; 323:883-897. [PubMed: 12417201]

20. Banci L, Bertini I, Ciofi-Baffoni S, Su XC, Miras R, Bal N, Mintz E, Catty P, Shokes JE, Scott RA. Structural basis for metal binding specificity: The N-terminal cadmium binding domain of the P1-type ATPase CadA. J. Mol. Biol. 2006; 356:638-650. [PubMed: 16388822]

21. Finney LA, O'Halloran TV. Transition metal speciation in the cell: Insights from the chemistry of metal ion receptors. Science. 2003; 300:931-936. [PubMed: 12738850]

22. Chen K, Yuldasheva S, Penner-Hahn JE, O'Halloran TV. An atypical linear Cu(I)-S2 center constitutes the high-affinity metal-sensing site in the CueR metalloregulatory protein. J. Am. Chem. Soc. 2003; 125:12088-12089. [PubMed: 14518983]

23. Ralle M, Lutsenko S, Blackburn NJ. X-ray absorption spectroscopy of the copper chaperone HAH1 reveals a linear two-coordinate $\mathrm{Cu}(\mathrm{I})$ center capable of adduct formation with exogenous thiols and phosphines. J. Biol. Chem. 2003; 278:23163-23170. [PubMed: 12686548]

24. Banci L, Bertini I, Ciofi-Baffoni S, Su XC, Borrelly GP, Robinson NJ. Solution structures of a cyanobacterial metallochaperone: Insight into an atypical copper-binding motif. J. Biol. Chem. 2004; 279:27502-27510. [PubMed: 15075318]

25. Borrelly GP, Blindauer CA, Schmid R, Butler CS, Cooper CE, Harvey I, Sadler PJ, Robinson NJ. A novel copper site in a cyanobacterial metallochaperone. Biochem. J. 2004; 378:293-297. [PubMed: 14711369]

26. Busenlehner LS, Pennella MA, Giedroc DP. The SmtB/ArsR family of metalloregulatory transcriptional repressors: Structural insights into prokaryotic metal resistance. FEMS Microbiol. Rev. 2003; 27:131-143. [PubMed: 12829264]

27. Liu T, Golden JW, Giedroc DP. A zinc(II)/lead-(II)/cadmium(II)-inducible operon from the cyanobacterium Anabaena is regulated by AztR, an R3N ArsR/SmtB metalloregulator. Biochemistry. 2005; 44:8673-8683. [PubMed: 15952774]

28. Rensing C, Mitra B, Rosen BP. The zntA gene of Escherichia coli encodes a Zn(II)-translocating P-type ATPase. Proc. Natl. Acad. Sci. U.S.A. 1997; 94:14326-14331. [PubMed: 9405611] 
29. Rensing C, Sun Y, Mitra B, Rosen BP. Pb(II)-translocating P-type ATPases. J. Biol. Chem. 1998); 273:32614-32617. [PubMed: 9830000]

30. Grass G, Fan B, Rosen BP, Franke S, Nies DH, Rensing C. ZitB (YbgR), a member of the cation diffusion facilitator family, is an additional zinc transporter in Escherichia coli. J. Bacteriol. 2001; 183:4664-4667. [PubMed: 11443104]

31. Pennella MA, Arunkumar AI, Giedroc DP. Individual metal ligands play distinct functional roles in the zinc sensor Staphylococcus aureus CzrA. J. Mol. Biol. 2006; 356:1124-1136. [PubMed: 16406068]

32. VanZile ML, Cosper NJ, Scott RA, Giedroc DP. The zinc metalloregulatory protein Synechococcus PCC7942 SmtB binds a single zinc ion per monomer with high affinity in a tetrahedral coordination geometry. Biochemistry. 2000; 39:11818-11829. [PubMed: 10995250]

33. Kuzmic P. Program DYNAFIT for the analysis of enzyme kinetic data: Application to HIV proteinase. Anal. Biochem. 1996; 237:260-273. [PubMed: 8660575]

34. VanZile ML, Chen X, Giedroc DP. Structural characterization of distinct a $3 \mathrm{~N}$ and a 5 metal sites in the cyanobacterial zinc sensor SmtB. Biochemistry. 2002; 41:9765-9775. [PubMed: 12146942]

35. Walkup GK, Imperiali B. Fluorescent chemosensors fr divalent zinc based on zinc finger domains. Enhanced oxidative stability, metal binding affinity, and structural and functional characterization. J. Am. Chem. Soc. 1997; 119:3443-3450.

36. Berjanskii MV, Neal S, Wishart DS. PREDITOR: A web server for predicting protein torsion angle restraints. Nucleic Acids Res. 2006; 34:W63-W69. [PubMed: 16845087]

37. Banci L, Bertini I, Del Conte R, Markey J, Ruiz-Duenas FJ. Copper trafficking: the solution structure of Bacillus subtilis CopZ. Biochemistry. 2001; 40:15660-15668. [PubMed: 11747441]

38. De Marac, NT.; Houmard, J. The Cyanobacteria. Elsevier Science Publishing Co., Inc.; New York; 1987.

39. Tong L, Nakashima S, Shibasaka M, Katsuhara M, Kasamo K. A novel histidine-rich CPx-ATPase from the filamentous cyanobacterium Oscillatoria brevis related to multiple-heavy-metal cotolerance. J. Bacteriol. 2002; 184:5027-5035. [PubMed: 12193618]

40. Pountney DL, Tiwari RP, Egan JB. Metal- and DNA-binding properties and mutational analysis of the transcription activating factor, B, of coliphage 186: A prokaryotic C4 zinc-finger protein. Protein Sci. 1997; 6:892-902. [PubMed: 9098899]

41. Busenlehner LS, Weng TC, Penner-Hahn JE, Giedroc DP. Elucidation of primary $(a(3) N)$ and vestigial (a(5)) heavy metal-binding sites in Staphylococcus aureus pI258 CadC: Evolutionary implications for metal ion selectivity of ArsR/SmtB metal sensor proteins. J. Mol. Biol. 2002; 319:685-701. [PubMed: 12054863]

42. Busenlehner LS, Cosper NJ, Scott RA, Rosen BP, Wong MD, Giedroc DP. Spectroscopic properties of the metalloregulatory $\mathrm{Cd}(\mathrm{II})$ and $\mathrm{Pb}(\mathrm{II})$ sites of $S$. aureus $\mathrm{pI} 258 \mathrm{CadC}$. Biochemistry. 2001; 40:4426-4436. [PubMed: 11284699]

43. Payne JC, ter Horst MA, Godwin HA. Lead Fingers: $\mathrm{Pb}^{2+}$ Binding to Structural Zinc-Binding Domains Determined Directly by Monitoring Lead-Thiolate Charge-Transfer Bands. J. Am. Chem. Soc. 1999; 121:6850-6855.

44. Magyar JS, Weng TC, Stern CM, Dye DF, Rous BW, Payne JC, Bridgewater BM, Mijovilovich A, Parkin G, Zaleski JM, Penner-Hahn JE, Godwin HA. Reexamination of lead(II) coordination preferences in sulfur-rich sites: Implications for a critical mechanism of lead poisoning. J. Am. Chem. Soc. 2005; 127:9495-9505. [PubMed: 15984876]

45. Banci L, Bertini I, Ciofi-Baffoni S, Gonnelli L, Su XC. A core mutation affecting the folding properties of a soluble domain of the ATPase protein CopA from Bacillus subtilis. J. Mol. Biol. 2003; 331:473-484. [PubMed: 12888353]

46. Okkeri J, Haltia T. The metal-binding sites of the zinc-transporting P-type ATPase of Escherichia coli. Lys(693) and Asp(714) in the seventh and eighth transmembrane segments of ZntA contribute to the coupling of metal binding and ATPase activity. Biochim. Biophys. Acta. 2006; 1757:1485-1495. [PubMed: 16890908]

47. Dutta SJ, Liu J, Mitra B. Kinetic analysis of metal binding to the amino-terminal domain of ZntA by monitoring metal-thiolate charge-transfer complexes. Biochemistry. 2005; 44:14268-14274. [PubMed: 16245943] 
48. Mitra B, Sharma R. The cysteine-rich amino-terminal domain of $\mathrm{ZntA}$, a $\mathrm{Pb}(\mathrm{II}) / \mathrm{Zn}(\mathrm{II}) / \mathrm{Cd}(\mathrm{II})$ translocating ATPase from Escherichia coli, is not essential for its function. Biochemistry. 2001; 40:7694-7699. [PubMed: 11412123]

49. Liu J, Dutta SJ, Stemmler AJ, Mitra B. Metal-binding affinity of the transmembrane site in ZntA: Implications for metal selectivity. Biochemistry. 2006; 45:763-772. [PubMed: 16411752]

50. Bunce J, Achila D, Hetrick E, Lesley L, Huffman DL. Copper transfer studies between the Nterminal copper binding domains one and four of human Wilson protein. Biochim. Biophys. Acta. 2006; 1760:907-912. [PubMed: 16632204]

51. Banci L, Bertini I, Ciofi-Baffoni S, Chasapis CT, Hadjiliadis N, Rosato A. An NMR study of the interaction between the human copper(I) chaperone and the second and fifth metal-binding domains of the Menkes protein. FEBS J. 2005; 272:865-871. [PubMed: 15670166]

52. Wernimont AK, Huffman DL, Lamb AL, O'Halloran TV, Rosenzweig AC. Structural basis for copper transfer by the metallochaperone for the Menkes/Wilson disease proteins. Nat. Struct. Biol. 2000; 7:766-771. [PubMed: 10966647]

53. Thelwell C, Robinson NJ, Turner-Cavet JS. An SmtB-like repressor from Synechocystis PCC 6803 regulates a zinc exporter. Proc. Natl. Acad. Sci. U.S.A. 1998; 95:10728-10733. [PubMed: 9724772]

54. Cavet JS, Borrelly GP, Robinson NJ. Zn, Cu and Co in cyanobacteria: Selective control of metal availability. FEMS Microbiol. Rev. 2003; 27:165-181. [PubMed: 12829266]

55. Banerjee S, Wei B, Bhattacharyya-Pakrasi M, Pakrasi HB, Smith TJ. Structural determinants of metal specificity in the zinc transport protein ZnuA from Synechocystis 6803. J. Mol. Biol. 2003; 333:1061-1069. [PubMed: 14583199]

56. Waldron KJ, Tottey S, Yanagisawa S, Dennison C, Robinson NJ. A periplasmic iron binding protein contributes towards inward copper supply. J. Biol. Chem. 2007; 282:3837-3846. [PubMed: 17148438]

57. Liu T, Nakashima S, Hirose K, Uemura Y, Shibasaka M, Katsuhara M, Kasamo K. A metallothionein and CPx-ATPase handle heavy-metal tolerance in the filamentous cyanobacterium Oscillatoria brevis. FEBS Lett. 2003; 542:159-163. [PubMed: 12729917]

58. Huckle JW, Morby AP, Turner JS, Robinson NJ. Isolation of a prokaryotic metallothionein locus and analysis of transcriptional control by trace metal ions. Mol. Microbiol. 1993; 7:177-187. [PubMed: 8446025]

59. Blindauer CA, Harrison MD, Robinson AK, Parkinson JA, Bowness PW, Sadler PJ, Robinson NJ. Multiple bacteria encode metallothioneins and SmtA-like zinc fingers. Mol. Microbiol. 2002; 45:1421-1432. [PubMed: 12207707]

60. Blindauer CA, Harrison MD, Parkinson JA, Robinson AK, Cavet JS, Robinson NJ, Sadler PJ. A metallothionein containing a zinc finger within a four-metal cluster protects a bacterium from zinc toxicity. Proc. Natl. Acad. Sci. U.S.A. 2001; 98:9593-9598. [PubMed: 11493688]

61. Grossoehme NE, Akilesh S, Guerinot ML, Wilcox DE. Metal-binding thermodynamics of the histidine-rich sequence from the metal-transport protein IRT1 of Arabidopsis thaliana. Inorg. Chem. 2006; 45:8500-8508. [PubMed: 17029360] 


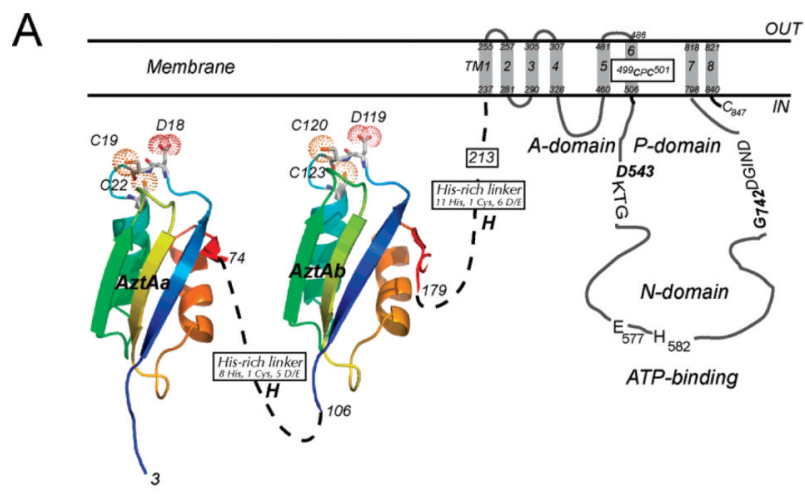

B

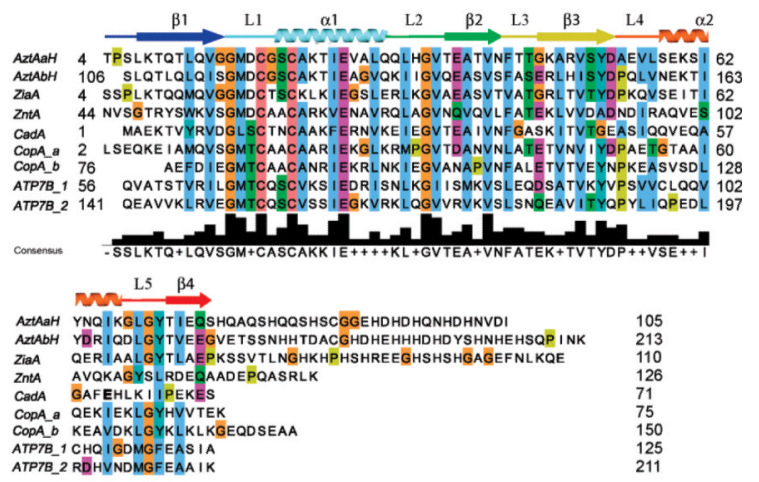

Figure 1.

(A) Schematic representation of the domain structure of AztA showing the two tandem MBDs followed by an $\approx 30$-residue hydrophilic His-rich linker. The predicted eight transmembrane helices, cytosolic ATP binding domains (N and P), and actuator domain (A), and putative $\mathrm{CPC}$ intramembrane zinc transport site are shown. The homology models of the AztA a-MBD and b-MBD were generated using B. subtilis CopAa (PDB entry 1OPZ) as a template using Swiss-Model (http://swissmodel.expasy.org//SWISS-MODEL.html). (B) Sequence alignment of the N-terminal region of AztA with analogous domains associated with other divalent or monovalent CPx-ATPases. The sequences are the first and second MBDs of Anabaena PCC 7120 AztA, ZiaA from Synechocystis spp. PCC 6803, ZntA from E. coli, CopA_a and CopA_b from B. subtilis, and the first and second MBDs from the Wilson disease ATPase, ATP7B. The deduced secondary structure derived for AztA ${ }^{\mathrm{aH}}$ is also shown. 

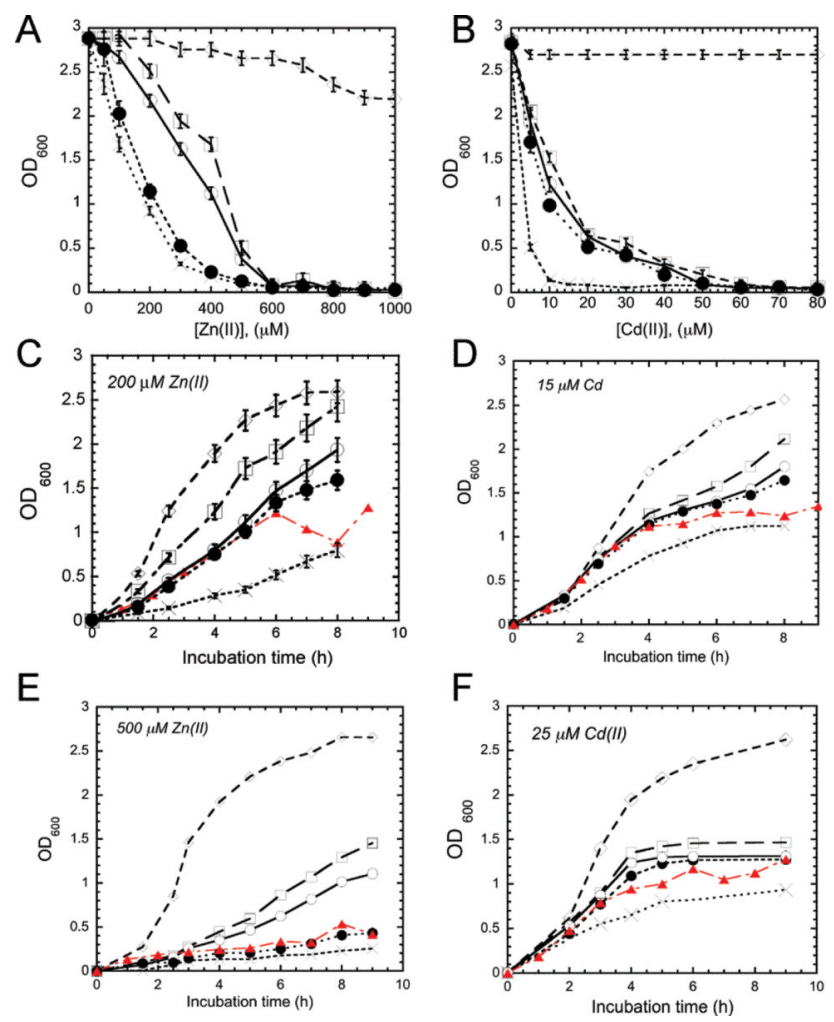

Figure 2.

Zinc and cadmium resistance of $\mathrm{Zn} / \mathrm{Cd}$ hypersensitive E. coli GG48 transformed with azt operons containing azt $A$ metal binding missense mutations. Representative data were derived from duplicate or triplicate measurements for E. coli GG48 transformed with pET3a vector (X), pETazt-C19S/C22S/C120S/C123S (red triangles), pETazt-C19S/C22S (black circles), pETazt-C120S/C123S (white circles), and pETazt (white squares) relative to an isogenic wild-type W3100 strain (white diamonds). 



Figure 3.

Representative anaerobic titrations of $\mathrm{Zn}$ (II) into a mixture of mag-fura-2 and purified $\operatorname{AztA}^{\mathrm{aHbH}}(\mathrm{A}), \mathrm{AztA}^{\mathrm{aH}}(\mathrm{B})$, or C19S/C22S AztA ${ }^{\mathrm{aHbH}}(\mathrm{C})$ in buffer C [5 mM Mes and 0.2 M $\mathrm{NaCl}\left(\mathrm{pH}\right.$ 6.5)]. For panel A, mag-fura-2 $(10.0 \mu \mathrm{M})$ and $\mathrm{AztA}^{\mathrm{aHbH}}(20.0 \mu \mathrm{M})$ were used. For panel B, 7.0 $\mu \mathrm{M}$ mag-fura-2 was mixed with $18.2 \mu \mathrm{M} \mathrm{Azt}{ }^{\mathrm{aH}}$. For panel C, $10.0 \mu \mathrm{M}$ mag-fura-2 was mixed with $20.0 \mu \mathrm{M}$ C19S/C22S AztA ${ }^{\mathrm{aHbH}}$. The absorbance changes at 366 (O) and $325 \mathrm{~nm}(\mathrm{O})$ were monitored and plotted as a function of total $\mathrm{Zn}$ (II) concentration. The solid lines represent a simultaneous, nonlinear, least-squares fitting curve generated by Dynafit to 2:1 stepwise binding models (defined by $K_{\mathrm{Zn} 1}$ and $K_{\mathrm{Zn} 2}$; see the text) for $\mathrm{AztA}^{\mathrm{aHbH}}$, a $1: 1$ model for $\left.\mathrm{AztA}^{\mathrm{aH}}\left[K_{\mathrm{Zn}}\right)(9.3 \pm 1.5) \times 10^{7} \mathrm{M}^{-1}\right]$, and an equimolar mixture of sites model for C19S/C22S AztA ${ }^{\mathrm{aHbH}}$ [see Materials and Methods; $\left.K_{\mathrm{Zn}}{ }^{\mathrm{A}}\right)(8.4 \pm 2.8) \times$ $10^{8} \mathrm{M}^{-1}$, and $\left.K_{\mathrm{Zn}}{ }^{\mathrm{B}}=(7.4 \pm 1.2) \times 10^{6} \mathrm{M}^{-1}\right]$ with $K_{\mathrm{Zn}}$ (mag-fura-2) fixed at $5.0 \times 10^{7} \mathrm{M}^{-1}$. 

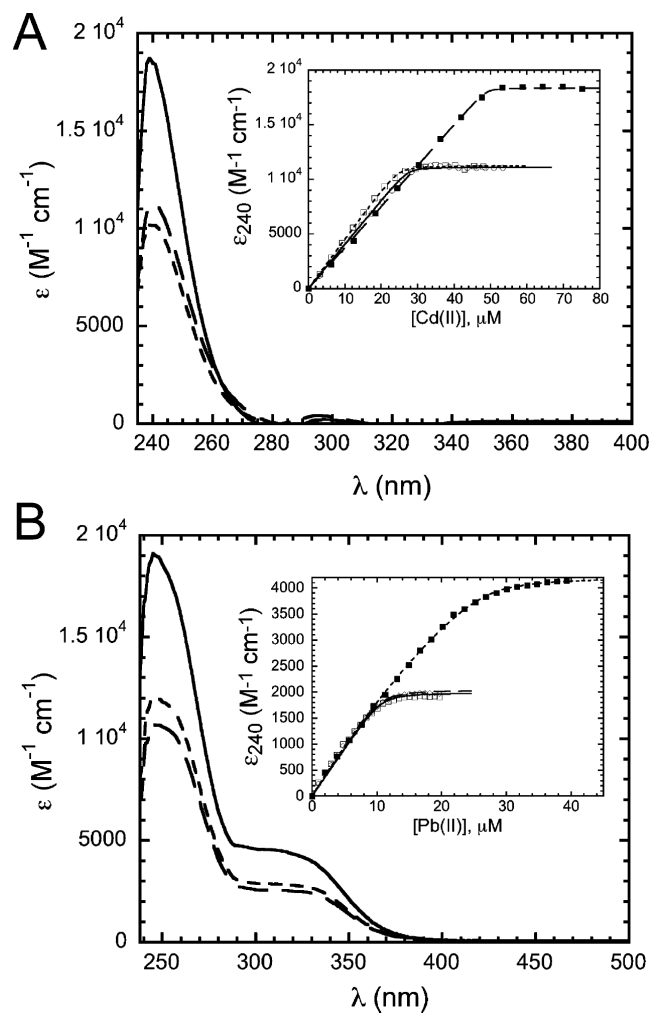

Figure 4.

(A) Optical absorption spectra of 1:1 Cd(II)-saturated AztA ${ }^{\mathrm{aHbH}}(-), 0.5: 1 \mathrm{Cd}(\mathrm{II})$-saturated $\mathrm{AztA}^{\mathrm{aH}}(---)$, and 0.5:1 Cd-(II) saturated C19S/C22S AztA ${ }^{\mathrm{aHbH}}(---)$. The inset shows anaerobic $\mathrm{Cd}(\mathrm{II})-\mathrm{Azt} A$ binding isotherms $\left\{\epsilon_{240}\right.$ vs total [Cd(II)], $50 \mu \mathrm{M}$ protein $\}$ generated from the optical spectra of $\operatorname{AztA}^{\mathrm{aHbH}}(\mathbf{\square}), \operatorname{AztA}^{\mathrm{aH}}(\square)$, and C19S/C22S AztA ${ }^{\mathrm{aHbH}}(\bigcirc)$. The smooth curve drawn through the data points reflects a $K_{\mathrm{Cd}}$ of $>5 \times 10^{7} \mathrm{M}^{-1}$, a lower limit given the high protein concentration that was used. (B) Optical absorption spectra of 1:1 $\mathrm{Pb}(\mathrm{II})$-saturated $\mathrm{AztA}^{\mathrm{aHbH}}(-), 0.5: 1 \mathrm{~Pb}(\mathrm{II})$-saturated AztA ${ }^{\mathrm{aH}}(---)$, and 0.5:1 Pb(II)saturated $\mathrm{C} 19 \mathrm{~S} / \mathrm{C} 22 \mathrm{~S} \mathrm{AztA}^{\mathrm{aHbH}}\left({ }_{--}\right)$. The inset shows anaerobic binding isotherms $\left\{\epsilon_{320}\right.$ vs total $[\mathrm{Pb}(\mathrm{II})], 20 \mu \mathrm{M}$ protein $\}$ generated from the optical spectra of $\mathrm{AztA}^{\mathrm{aHbH}}(\mathbf{\square})$, $\operatorname{AztA}^{\mathrm{aH}}(\square)$, and C19S/C22S AztA ${ }^{\mathrm{aHbH}}(\diamond)$ obtained upon titration of $\mathrm{Pb}(\mathrm{II})$. For AztA ${ }^{\mathrm{aHbH}}$, the solid line represents a least-squares fitted curve with a $K_{\mathrm{Pb}}$ of $8.0 \times 10^{7} \mathrm{M}^{-1}$. For $\mathrm{AztA}^{\mathrm{aH}}$ and C19S/C22S AztA ${ }^{\mathrm{aHbH}}$, the smooth curve reflects a lower limit for a $K_{\mathrm{Pb}}$ of $\geq 1$ $\times 10^{8} \mathrm{M}^{-1}$. 

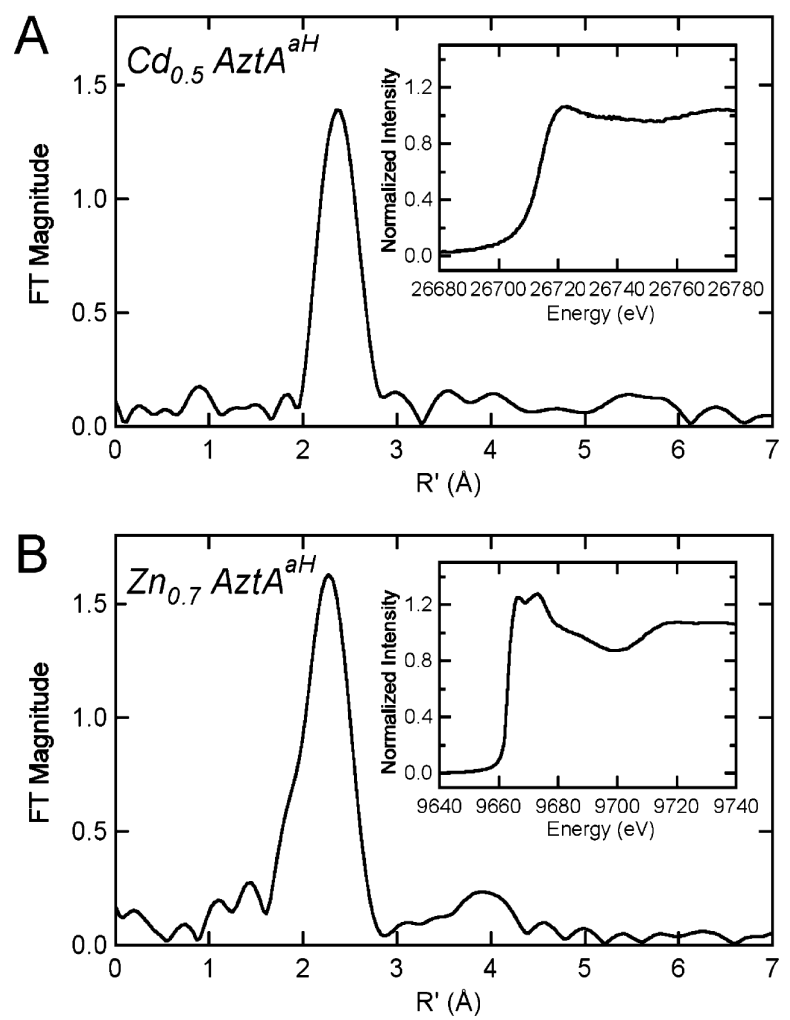

Figure 5.

EXAFS analysis of $\mathrm{Zn}(\mathrm{II})-$ and Cd(II)-bound $\mathrm{AztA}^{\mathrm{aH}}$. (A) Fourier transform $\left(k=2-12 \AA^{-1}\right.$; $k^{3}$ weighting) of the $\mathrm{Cd}$ K-edge EXAFS of the $\mathrm{Cd}(\mathrm{II})_{0.5}-\mathrm{AztA}^{\mathrm{aH}}$ complex. (B) Fourier transform $\left(k=2-12 \AA^{-1} ; k^{3}\right.$ weighting) of the $\mathrm{Zn} \mathrm{K}$-edge EXAFS of the $\mathrm{Zn}(\mathrm{II})_{0.7}-\mathrm{AztA}{ }^{\mathrm{aH}}$ complex. Cadmium and zinc K-edge X-ray absorption near-edge spectra are shown in the insets of panels A and B, respectively. Parameters that define the best fits to these data are compiled in Table SII. 

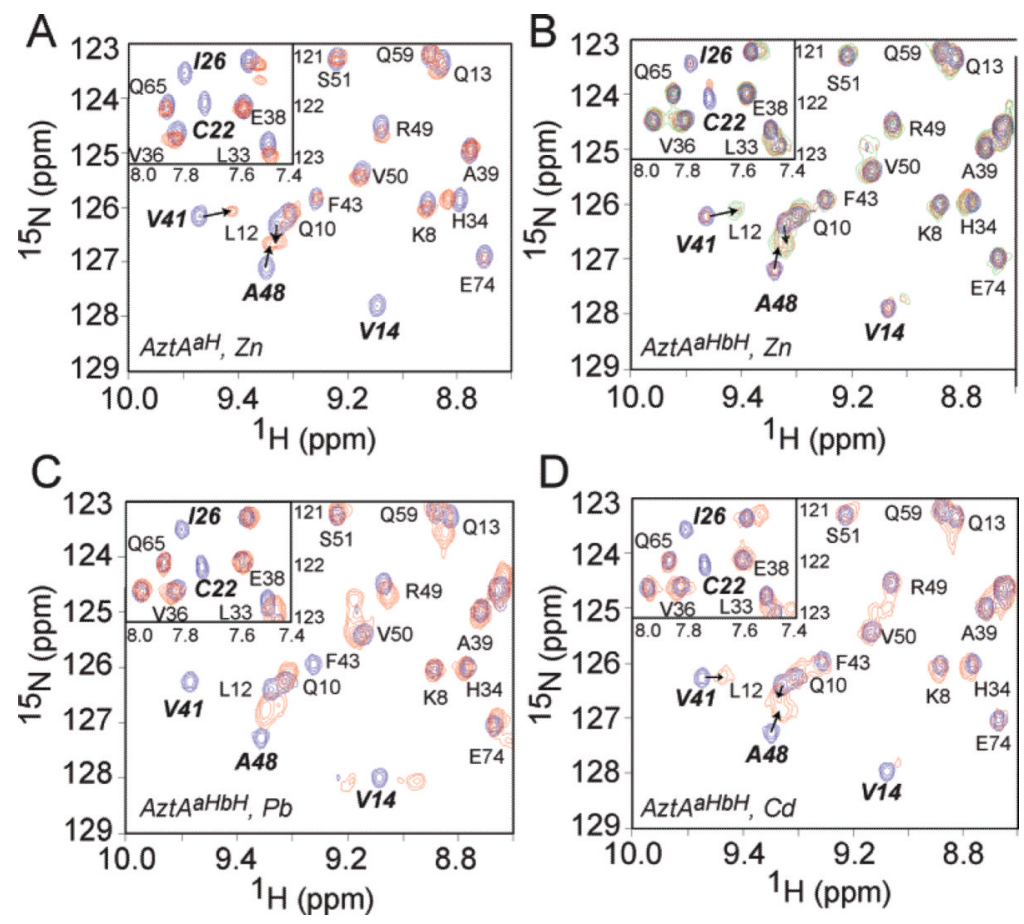

Figure 6.

Superposition of selected regions of the ${ }^{1} \mathrm{H}-{ }^{15} \mathrm{~N}$ HSQC spectra of (A) apo-AztA ${ }^{\text {aH }}$ (blue cross-peaks) and apo-AztA ${ }^{\mathrm{aH}}$ with 1 molar equiv of $\mathrm{Zn}$ (II) (red contours), (B) apo$\mathrm{AztA}^{\mathrm{aHbH}}$ (blue contours) mixed with 1 molar equiv of $\mathrm{Zn}(\mathrm{II})$ (red contours) and 2 molar equiv of $\mathrm{Zn}$ (II) (green contours), (C) apo-AztA ${ }^{\mathrm{aHbH}}$ (blue contours) mixed with 1 molar equiv of saturating $\mathrm{Cd}(\mathrm{II})$ (red contours), and (D) apo-AztA ${ }^{\mathrm{aHbH}}$ (blue contours) mixed with 1 molar equiv of saturating $\mathrm{Pb}(\mathrm{II})$ (red contours). Note that the movement of the $\mathrm{Val} 41$ and Ala48 cross-peaks in the $\beta 2-\beta 3$ loop in the AztA ${ }^{\mathrm{aHbH}}$ spectrum (panel B) is maximal only when both the a- and b-MBDs are filled with $\mathrm{Zn}$; in contrast, this perturbation appears to be maximal with only 1 molar equiv of $\mathrm{Cd}$ and $\mathrm{Pb}$ (panels $\mathrm{C}$ and $\mathrm{D}$ ). In the insets, extensive line broadening of both Cys22 and Ile26 is also reporting on the metal occupancy of the DCXXC region in the a-MBD. 


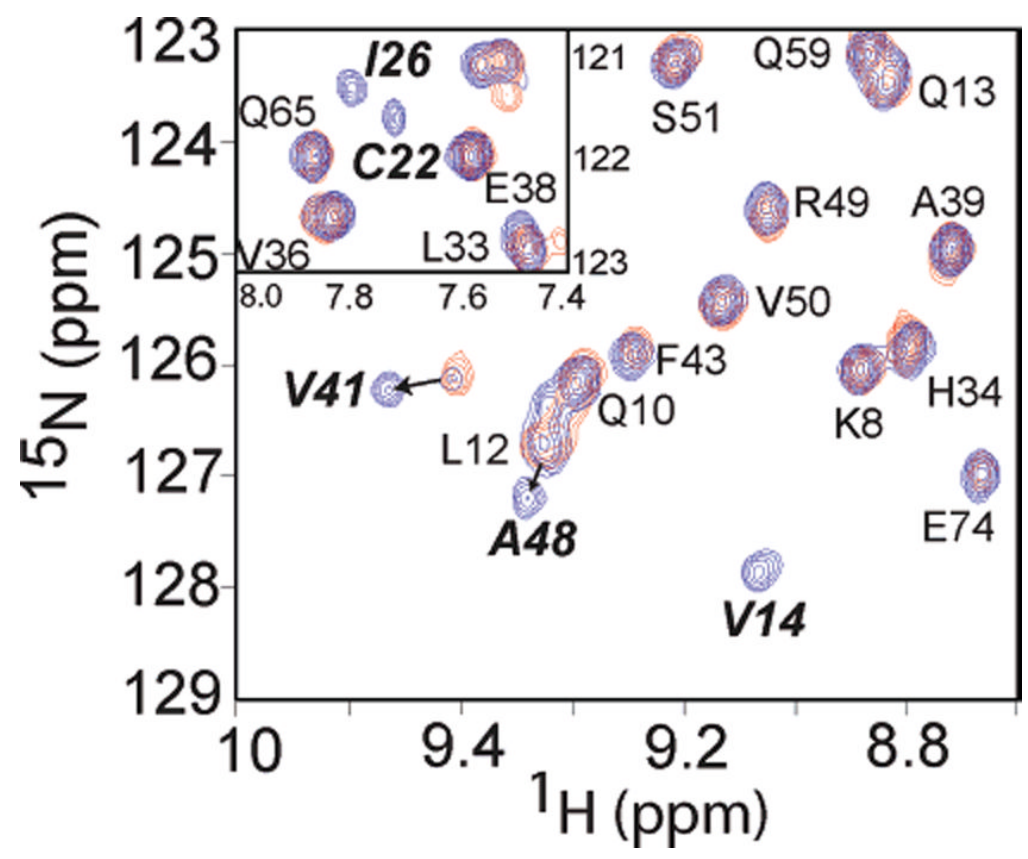

Figure 7.

Transfer of $\mathrm{Zn}$ (II) from $\mathrm{Zn}$ (II)-loaded uniformly ${ }^{15} \mathrm{~N}$-labeled AztA ${ }^{\mathrm{aH}}$ to unlabeled apoC19S/C22S AztA ${ }^{\mathrm{aHbH}}$. Superposition of ${ }^{1} \mathrm{H}-{ }^{15} \mathrm{~N}$ HSQC spectra of a 1:1 complex of $\mathrm{Zn}$ (II) and $\mathrm{AztA}^{\mathrm{aH}}$ alone (red contours) or in the presence of unlabeled apo-C19S/C22S AztA ${ }^{\mathrm{aHbH}}$ at a 1:1 molar ratio (blue contours). Note that resonances corresponding to Val14, Cys22, Ile26, Val41, and Ala48 return to their characteristic positions in apo-AztA ${ }^{\mathrm{aH}}$ upon addition of a stoichiometric amount of apo-b-MBD, indicative of $\mathrm{Zn}$ (II) transfer. In the inset, extensive line broadening of both Cys 22 and Ile26 also reports on the metal occupancy of the DCXXC region in the a-MBD. 


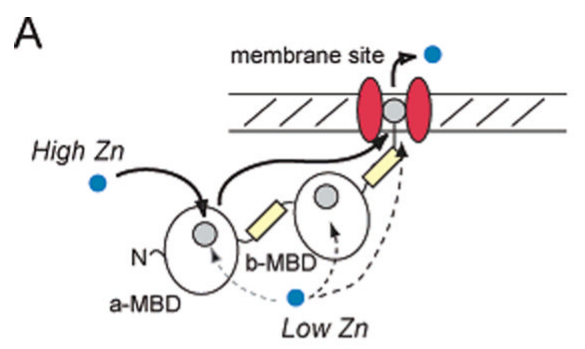

B
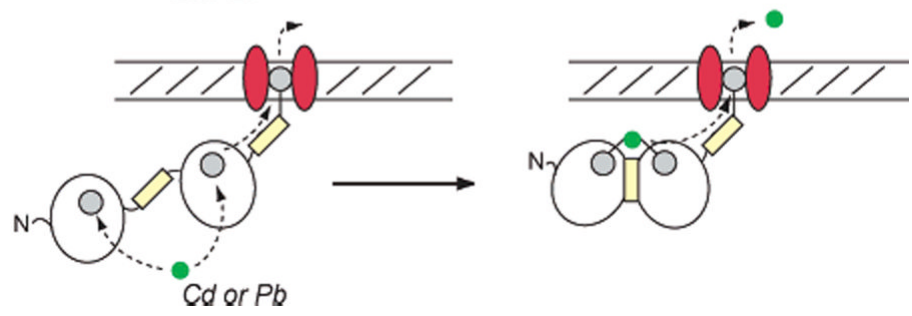

Figure 8.

Hypothetical model that illustrates plausible pathways for the transfer of (A) $\mathrm{Zn}$ or (B) Cd/ $\mathrm{Pb}$ from the cytosolic MBD region of AztA to the transmembrane site, and on to the other side of the membrane, consistent with the data presented here. At low cytosolic $\mathrm{Zn}$ loads, the metal can interact with the a-MBD, b-MBD, or transmembrane site in a manner dictated by their relative affinities. At high intracellular $\mathrm{Zn}$ loads, metal interacts with the low-affinity aMBD to maximally stimulate the transporter. For $\mathrm{Cd} / \mathrm{Pb}$, these ions form a trapped interMBD complex. Metal binding sites are indicated by the filled gray circles, within the aMBD, b-MBD, and the transmembrane sites indicated (49). The contribution of the His-rich domains (yellow rectangles) to $\mathrm{Zn}$ (II) transport is not yet known; however, they likely bind $\mathrm{Zn}$ (II) (61) and may well influence rates of transport of metal through the membrane. 